\title{
Drought, Hurricane, or Wildfire? Assessing the Trump Administration's Anti-Science Disaster
}

\author{
SCOTT FRICKEL \\ BROWN UNIVERSITY \\ CHRISTOPHER REA ${ }^{2}$ \\ THE OHIO STATE UNIVERSITY
}

\begin{abstract}
We describe the Trump Administration as an "anti-science disaster" and approach study of the phenomenon as other disaster researchers might study the impacts of a drought, hurricane, or wildfire. An important, but rare, element of disaster research is identification of baseline data that allow scientific assessment of changes in social and natural systems. We describe three potential baselines for assessing the nature and impact of Trump's anti-science rhetoric and (in)action on science, science policy, and politics.
\end{abstract}

\section{Keywords}

Trump Administration; science policy; disasters; anti-science; methodology; politics of knowledge

We count ourselves among those who believe in the responsibility of liberal democratic states to provide rational policies for addressing society's many problems and that science has a prominent role to play in identifying problems, developing policy, and in policy assessment. From this standpoint, the Trump Administration looks to us like an unmitigated disaster, complete with predictably unpredictable "tweet storms."

As everyone knows, disasters come in many forms. They can creep up slowly and press down upon us with steadily more severe effects, like a drought. They can devastate broadly, but provide ample warning, like a hurricane. They can spring up suddenly like a wildfire and leave erratic paths of destruction in their wake. All disasters, though, call our attention to the urgent need for new knowledge; and all seem to mobilize small armies of researchers who swarm into disaster-torn places to assess damage, diagnose causes, document impacts, and advance procedures for recovery. Disasters prompt calls for science to replace ignorance and uncertainty with new knowledge and renewed clarity. But disasters also raise difficult epistemic questions,

. Scott Frickel, Email: scott_frickel@brown.edu

. Christopher Rea, Email: rea.115@osu.edu

Copyright (c) 2020 (Scott Frickel and Christopher Rea). Licensed under the Creative Commons Attribution Noncommercial No Derivatives (by-nc-nd). Available at estsjournal.org. 
like whether new knowledge is useful in such contexts; how that knowledge sits within broader and always unequal social and political fields; and whether it is meaningful to draw distinctions between science and politics or research and activism.

For academics living in New Orleans in the aftermath of hurricane Katrina (2005-7) drawing such distinctions made little empirical sense. In that context, basic research became a form of local activism because the questions that researchers were pursuing mattered to the everyday and because the results of those studies were enveloped in a politics of loss and recovery. This was true for engineers researching the structural failure of a flood barrier, geologists assessing patterns of sediment splays, ecologists documenting wetlands that had disappeared overnight, demographers investigating the dynamics of repopulation and resettlement, and ethnographers bringing to light and explaining social exclusion and the new forms of inequality that were emerging between flooded and unflooded neighborhoods. Conducting serious research during this period was-inescapably-a political act.

A similar sense of epistemic uncertainty today brings questions about "the demarcation problem" into sharp relief for those of us who study environmental knowledge and regulatory science. While the context is vastly different than post-Katrina New Orleans, a sense of urgency and the inescapably political nature of research once again grip us. As in other calamitous contexts, we busily set to work with our satellites, our statistics, and our notepads, documenting and diagnosing the causes and consequences of what feels to us like the anti-science Trump disaster and the "post-truth" era his Administration represents (Kelkar 2019).

But as anyone who has studied them knows well, characterizing and explaining disasters requires establishing good baselines for comparison and assessment. Our ability to explain these catastrophic events, rather than to merely describe them, depends on it. So we ask, what is the baseline? Absent the ability to carefully pre-plan our research, what kinds of change do we measure, especially when it seems as though virtually everything around us has changed, including the public embrace—or dismissal—of scientific knowledge by the president himself? In short, if the Trump Administration really is a disaster, what kind of disaster is it? What comparative baselines should we use to make such an assessment? There are several research routes to follow.

Although presidential anti-science has been around since at least the 1920s (Otto 2012), a good starting point for us is to develop a comparison with the 2000-2008 administration of George W. Bush. It might be especially useful to dust off an article published in Dissent in 2005 by Abby Kinchy and Daniel Kleinman, who remind us that Trump's is not the first Oval Office to sustain an assault on science. Like Team Trump, the George W. Bush Administration also:

- ignored science when it was politically convenient;

- had a habit of making new policy based on ideology rather than evidence;

- manipulated information, inserted bias into scientific and regulatory processes, censored knowledge and suppressed reports;

- stacked science advisory committees with people known to support industry positions; 
- deregulated like hell (or tried to); and

- fueled a cottage industry of popular and academic writing documenting and decrying the anti-science attacks.

Kinchy and Kleinman use the anti-science politics prominent during the Bush administration to illustrate the need for a further democratization of science and science policy through public debates organized around difficult questions about social values and interests rather than narrowly technical questions that lead to technocratic decision-making. The lesson they offer is an important one and resonates as deeply today as when their essay was first published.

But the anti-science stance of the Bush administration also strikes a contrast to that of the Trump disaster. The former fabricated facts to justify the invasion of Iraq, for example, but it did not question the need for facts at all. If anything, misrepresentations of evidence perpetrated by Bush and, infamously, by Colin Powell as he made the case for war at the United Nations, underscored that administration's acceptance of the principal that, on some level, facts matter (Zarefsky 2007). Likewise, when Bush announced in 2001 that the United States would not support the international Kyoto Protocol to combat climate change, the president called on Americans to "develop with our friends and allies and nations throughout the world an effective and science-based response to the issue of global warming" (Bush 2001, emphasis added). While casting doubt on its findings, Bush even highlighted an influential report by the National Academy of Sciences on the anthropogenic causes of climate change. Bush's words may be have been hollow and perhaps disingenuous, but one can hardly imagine Trump even bothering to pay lip service to science and the careful, conservative reasoning of a National Academy of Sciences report.

We will not continue to develop the Bush-Trump comparison or turn to other comparable anti-science presidencies, notably Reagan's (Mooney 2005), but we hope the point is clear: carefully developing historical baselines like these can be extremely useful. Read as historical documents, earlier critiques of other administrations, like Kinchy and Kleinman's, can help us develop a more rational assessment of the severity of Trump's attacks on science, including by drawing out their roots in earlier anti-science presidencies and political movements.

A second strategy for establishing comparative baselines is to examine the extent and persistence of the gap between the Trump administration's rhetorical attacks on science, on the one hand, and the material implementation of associated policy, on the other. In early March of 2019, for example, the Administration announced a new federal budget that proposed cutting funding to the National Institutes for Health by about $\$ 5$ billion or roughly 13\% (Ledford et al. 2019). A similar level of cuts was proposed in the previous budget cycle, but those cuts materialized at a much lower level when Congress finally passed the budget in 2018. Trump had proposed a 30\% reduction in funding for the Environmental Protection Agency (EPA), for instance, but Congress maintained funding for EPA at $\$ 8.1$ billion, with no effective budget change (Davis 2018). Similarly, the administration has proposed a raft of drastic rule changes, ranging from narrowing the scope of the Clean Water Act (USACE and EPA 2019) to scaling back 
the Endangered Species Act (U.S. Fish and Wildlife Service 2018) to relaxing the EPA's approach to regulating carbon dioxide under the Clean Air Act (Keyes et al. 2019).

But there is a lot of redundancy built into our environmental bureaucracy that slows the pace of implementation of these proposed changes, and many of the most dramatic of Trump's proposals face robust court challenges and so are slowed further. By rule of the US Supreme Court in Massachusetts v. EPA (2007), for instance, the EPA must regulate carbon dioxide as a pollutant governed by the Clean Air Act, effectively forcing the Trump administration, however feebly, to grapple with the problem of rising $\mathrm{CO}_{2}$ emissions. Proposed changes to the scope of the Clean Water Act—in Trump's crosshairs since his campaign days (Rea 2018)—had only reached the mandated "public comment period" when we initially penned this essay (USACE and EPA 2019); that document garnered over 11,369 comments (most proposed rules receive few-to-zero comments).3 Any final rule, still pending, will certainly be litigated by environmental groups, likely all the way to the Supreme Court. Final legal judgment is unlikely before the 2020 election; a Democratic administration would almost certainly decline to appeal a loss in a lower court, allowing Trump's proposed rule change to slip like dust through the floorboards of history.

In short, examinations of the rhetorical-material gap suggest that the Trump disaster may wreak more havoc in the political-ideological realm, further undermining and polarizing science and knowledge production, than in the rubber-hits-the-road realm of on-the-ground policy (granting, of course, that the ideological and material processes are interdependent). The situation teases analogies to government and media constructions that anticipate far greater destruction from impending disasters than actually occurs, such as $\mathrm{Y} 2 \mathrm{~K}$ or similarly hyped "disasters." The more general point most relevant to our argument is that careful study of the coupling-or decoupling — of policy and rhetoric, and the politics of knowledge this engenders, is a fruitful and critical point of departure for understanding the anti-science Trump disaster and its effects on knowledge production, policymaking, and, of course, responses to pressing socioecological problems themselves.

\footnotetext{
${ }^{3}$ When we researched and wrote the initial draft of this essay, in mid-April 2019, we found 63,203 public comments listed on regulation.gov, the multi-agency clearinghouse and online portal for public engagement with the federal rulemaking process. In mid-July, as we were revising the piece for publication and updating our analysis, we discovered that the number of public comments on the proposed change to the definition of "Waters of the United States" had not increased as we had expected, but instead had decreased nearly six-fold. We are not entirely sure what explains this cliff-drop; the reason is likely the consolidation of very similar or duplicate comments solicited by advocacy organizations. Filtering search results for "Mass Mail Campaign" comments only, for example, reveals that the Sierra Club drove a mass comment campaign that produced 74,908 nearly identical comments and that the National Resources Defense Council drove a similar campaign that produced 72,280 nearly identical comments. Several other mass campaigns produced tens-of-thousands more comments. The total number of individual comments on the proposed rule change was thus probably around 200,000. Each of these large-scale campaigns, however, is only counted as a single comment in final public-facing statistics presented on regulations.gov. How to count and weigh mass comments is a thorny political and administrative issue. Still, counting tens-of-thousands of comments from mass campaigns as single comments in public-facing statistics seems, prima facie, intended to minimize the visibility of mass opposition to regulatory changes. Arguably, this technocratic tactic impinges upon public access to a legitimate (and legally mandated) form of political dissent.
} 
There is a third basis for assessing the Trump disaster that we see as particularly promising and for which the data already exist: long-term trends in the erosion (in some areas) and accretion (in others) of employment levels and other resources devoted to science, knowledge production, and regulatory expertise. Hurricanes again offer a useful analogy. The 2005 hurricane season devastated the Louisiana Gulf Coast, with hurricanes Katrina and Rita wiping out an estimated 152 square miles of coastal wetlands (Couvillion et al. 2011). But the loss of land and vegetation associated with the storms was part of a longer-term trend. Since 1985, Louisiana wetlands have disappeared at a rate of 16.57 square miles per year (Ibid.). This broader pattern of loss exacerbated the impact of Katrina and Rita's devastating one-two punch on the Gulf's already frayed and increasingly vulnerable coastal ecosystem.

We can study the Trump Administration's impacts on the state's capacity to produce and implement science-based regulation using a similar strategy. The "rapid onset" political disaster of the past two years-measured in vacant seats on government scientific advisory boards (Union of Concerned Scientists 2018), plummeting enforcement actions at the EPA (Frederickson et al. 2018) or the mass mobilization of experts and science supporters (Fisher and Frickel 2018)—has occurred within the context of longer-term historical trends shaping the federal bureaucracy. These trends include the erosion of the resources needed for effective and proactive governance and enforcement of the law in some areas of the federal government, and the accretion of resources in other administrative areas. In this way, long-term federal employment data act as a proxy measure of the government's baseline capacity to mitigate, respond, and recover in the face of political disasters as well as natural ones (see Kates et al. 2006). Drawing from employment data provided by the US Office of Personnel Management (OPM), Figure 1 (next page) shows results from our preliminary analysis and offers a flavor of the longer-term dynamics we are studying.

The green lines in the figure highlight employment trends in agencies focused on environmental protection and natural resource management and use. These are agencies responsible for much of the on-the-ground implementation and enforcement of environmental laws, rules, and regulations, as well as research that provides some of the underlying science. Bold lines indicate the aggregated net trends of agencies focused on environment and natural resources (once again in green) and for the entire federal civilian workforce across all types of agencies (in black). The light grey lines in the background (unlabeled) are all other agencies and offices, regardless of type or focus. 


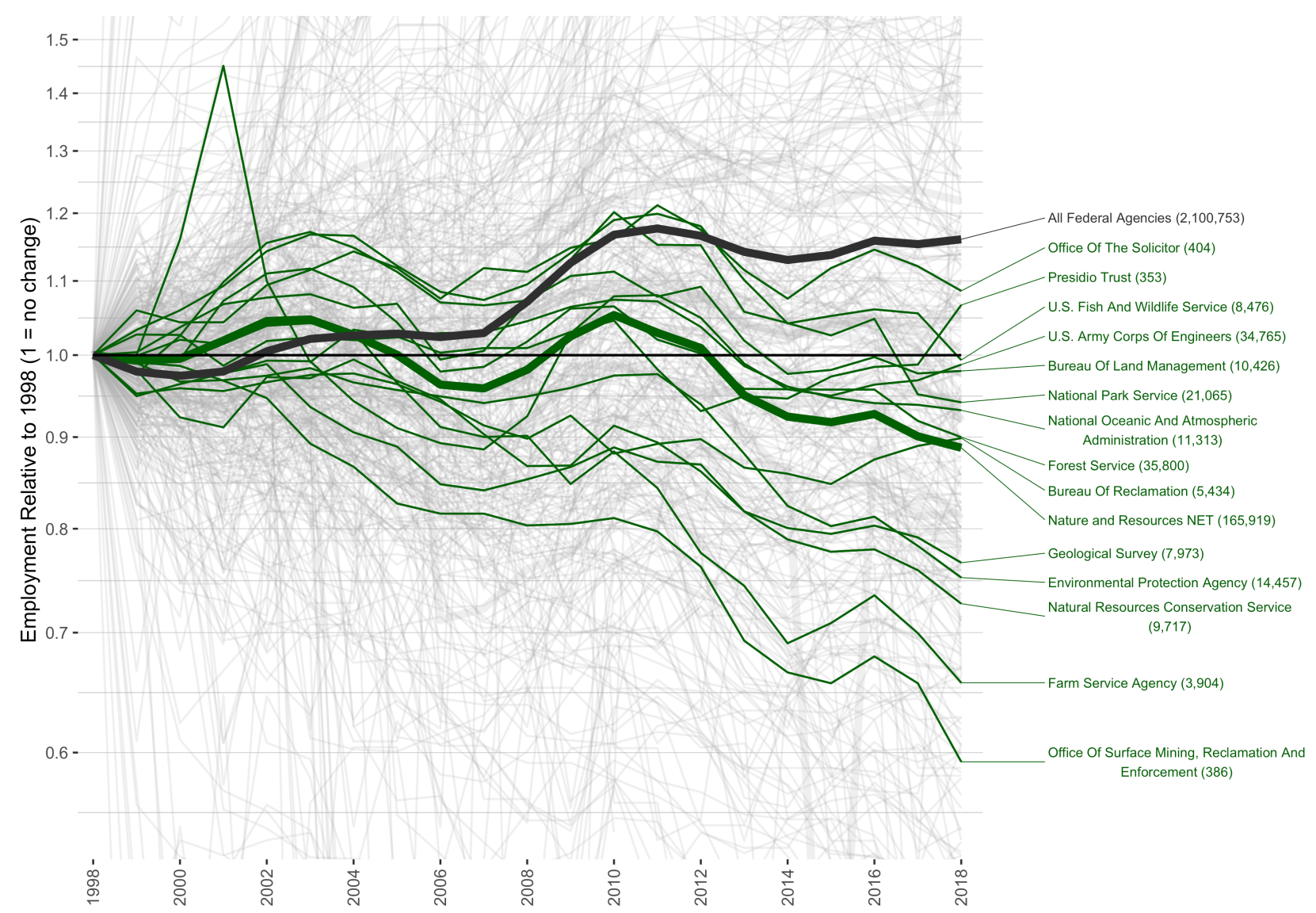

Figure 1. Changes in civil service employment in select US federal agencies, 1998-2018

Note: Values on the $\mathrm{Y}$ axis are indexed to employment levels in 1998: numbers above 1 indicate employment growth relative to 1998 levels; values less than 1 indicate erosion. Numbers in parentheses (right side) refer to total number of employees in each highlighted agency in 2018.

Source: US Office of Personnel Management. Data compiled and visualized by the authors.

The chart reveals several points of variation that help place the Trump Administration's recent attacks on science in a broader historical context. First, the federal workforce has actually grown by about $15 \%$ over the past 20 years, and barely changed at all in Trump's first two years in office: comparing September 2016 to September 2018 data, the total federal workforce, excluding the Department of Defense (DoD), declined by a miniscule 385 people, or $0.03 \%$ of 1.35 million non-DoD federal employees.

- Figure 1 includes civilian DoD employees; with those civilian employees included, the total federal workforce has actually grown by 3,715 people during Trump's first 21 months in office, to just over 2.1 million. All counts exclude employees from the following agencies: US Postal Service, Board of Governors of the Federal Reserve, Central Intelligence Agency, Defense Intelligence Agency, Foreign Service personnel at the State Department, National Geospatial-Intelligence Agency, National Security Agency, Office of the Director of National Intelligence, Office of the Vice President, Postal Regulatory Commission, Tennessee 
Second, this overall trend masks considerable internal heterogeneity, visible in the mess of gray background lines in Figure 1. To get a better sense of this internal variation, we compared trends in civil service employment in environmental protection and natural resource agencies to ten other categories of federal agency focus: commerce and information; crime and law; defense; education; foreign affairs; health and social welfare; public management and administration; money, banking, and finance; research, the arts, and science; and work and labor (analysis not shown). Of all eleven agency categories, only the highlighted environment and natural resource agencies fall uniformly below the net changes experienced by the federal government as a whole. (That is, all the green lines in Figure 1 fall below the bold, black line in 2018.) All but two of those agencies have shrunk in absolute employment size since 1998. The US Geological Survey, the EPA, and the Natural Resources Conservation Service (NRCS) were all roughly 25\% smaller by employment in 2018 than they were two decades earlier, in 1998. Collectively, these trends suggest that, while resource accretion and growth has characterized employment trends in many federal agencies and offices across the US government over the past 20 years, workforces at agencies focused on protecting the environment and managing natural resources have been systematically diminished relative to overall trends-a process that we now know began long before Donald Trump's election in November, 2016.

Like the long-disappearing wetlands of Louisiana's Gulf Coast, in other words, the institutions of government charged with protecting the environment and managing the use of natural resources have faced long-term processes of erosion. These erosion processes are uneven, and are likely driven by different mechanisms, to be sure. But it is also likely that gradual historical erosion of these institutions has increased their vulnerability today, in both absolute and relative terms, to the Trump Administration's more recent attempts to bulldoze environmental regulations and undermine agencies' ability to generate a supporting base of scientific and engineering research.

We are betting that this third approach to studying the Trump anti-science disaster will prove to be particularly instructive. To be sure, the preliminary analysis of federal employment data presented above raises more questions than we can currently answer. For example, are staff cuts at the Office of Natural Resource Revenue (formerly Minerals Management Service), which is responsible for managing offshore oil and gas leases, likely to have the same detrimental impacts on the environment as staff cuts at EPA or the NRCS? As staffing levels at environment and resource agencies have declined, has the disciplinary composition of agency experts also shifted in ways that reflect more "anti-science" or "pro-growth" goals? That is, are we seeing petroleum and chemical engineers replace environmental and civil engineers? Or economists replacing ecologists? What impacts will the shifting composition of disciplinary expertise have on scientific education and the science and engineering workforce? What kinds of knowledge will be marginalized as a result?

We are pursuing such questions as systemically as possible. Doing so, we believe, will help chart a course of inquiry bridging the political sociology of science and technology during

Valley Authority, and the White House Office. Individual agency counts in Figure 1 only sum to 164,473 (not the total 165,919 for "Nature and Resources NET") because several very small offices are not shown. 
the Trump era (see e.g. Hess 2020) with new research on the "sociology of loss" (see e.g. Elliott 2018), which calls for us to examine "what does, will, or must disappear" in the context of climate change (p. 301)—and, by extension, any number of other "environmental" problems. These two projects and our own are indelibly connected. Harnessing longitudinal data to study longer term dynamics of institutional change will provide a deeper understanding of the nature of the metaphorical and all-too-real disasters-political and ecological-currently confronting the United States and the planet. In a moment of urgency, this strategy guards against rash overstatement and rushed judgments, helping to ensure that assessments of the socioecological impacts of the Trump Administration are rigorously attentive to the fundamental methodological problem of baseline measurement.

\section{Author Biography}

Scott Frickel is Professor of Sociology and Environment and Society at Brown University and Community Engagement Core Leader for the Brown Superfund Research Program. Interested in how nature, knowledge, and politics combine, his latest book, with James R. Elliott, is a comparative study of urban socioecological change titled Sites Unseen: Uncovering Hidden Hazards in American Cities (Russell Sage Foundation and the ASA Rose Series in Sociology, 2018).

\section{Author Biography}

Chris Rea is Assistant Professor of Public Affairs and (by courtesy) Sociology in the John Glenn College of Public Affairs at The Ohio State University. He is also Core Faculty in the Sustainability Institute at Ohio State. His first book project, Economy and Ecology, is a study of the causes and consequences of the increasing integration of markets into systems of nature protection, theorized through a comparative examination of the development of "ecological offsetting" schemes in Germany and in the United States. Chris also likes to go outside and to ride bikes whenever he can.

\section{Acknowledgements}

The authors thank the Institute at Brown for Environment and Society (IBES), which, by way of a generous Voss Postdoctoral Research Associate position for Chris, provided the material support that made it possible to write this piece and to begin a larger, related project on the politics of erosion in the environmental state. We also thank the ESTS editor and anonymous reviewer for helpful comments on a previous version of this essay, Katie Vann for astute copy-editing, and Joe Harris for organizing the panels on Science and Technology Studies in an Era of Anti-Science at the Eastern Sociological Society Annual Meeting that first inspired this essay. 


\section{References}

Bush, George W. 2001. "President Bush Discusses Global Climate Change." The White House (June 11). $\quad$ https://georgewbush-whitehouse.archives.gov/news/releases/2001/06/20010611-2.html. Accessed July 19, 2019.

Couvillion, B. R., Baras, J. A., Steyer, G. D., Sleavin, W., Fischer, M., Beck, H., et al. (2011). Land area change in coastal Louisiana from 1932 to 2010: U.S. Geological Survey Scientific Investigations Map 3164, scale 1:265,000. https://pubs.usgs.gov/sim/3164/. Accessed July 20, 2019.

Davis, Julie Hirschfeld. 2018. “Spending Plan Passed by Congress Is a Rebuke to Trump. Here's Why." The New York Times (March 23). https: / / www.nytimes.com/2018/03/22/us/politics/trump-government-spendingbill.html. Accessed July 20, 2019.

Diffenbaugh, Noah S., Daniel L. Swain, and Danielle Touma. 2015. "Anthropogenic warming has increased drought risk in California." PNAS 112(13): 3931-3936.

Elliott, Rebecca. 2018. "Sociology of Climate Change as a Sociology of Loss." European Journal of Sociology 59(3): 301-337.

Fisher, Dana R. and Scott Frickel. 2018. "Will Scientists Gear Up for Activism in the Age of Trump?" The American Prospect (July 12). https:// prospect.org/article/will-scientistsgear-activism-age-trump.

Fredrickson, Lief, Marianne Sullivan, Christopher Sellers, Jennifer Ohayon, Ellen Kohl, Sarah Lamdan, Alissa Cordner, Alice Hu, Katarzyna Kaczowka, Natalia Navas, Linda Wicks, and the Environmental Data Governance Initiative. 2018. "A Sheep in the Closet: The Erosion of Enforcement at the EPA." The Environmental Data Governance Initiative (May 2019). https://envirodatagov.org/wp-content/uploads/2018/11/Sheep-in-theCloset.pdf. Accessed July 20, 2019.

Hess, David J. 2020. "The Sociology of Ignorance and Post-Truth Politics." Sociological Forum, forthcoming.

Kates, R. W., C. E. Colten, S. Laska, and S. P. Leatherman. 2006. "Reconstruction of New Orleans after Hurricane Katrina: A Research Perspective." PNAS 103(40):14653-14660.

Kelkar, Shreeharsh. 2019. "Post-truth and the Search for Objectivity: Political Polarization and the Remaking of Knowledge Production." Engaging Science, Technology, and Society 5: 86-106.

Keyes, Amelia Trafton, Kathleen Fallon Lambert, Dallas Burtraw, Jonathan J. Buonocore, Jonathan I. Levy, and Charles T. Driscoll. 2019. “The Affordable Clean Energy Rule and the Impact of Emissions Rebound on Carbon Dioxide and Criteria Air Pollutant Emissions." Environmental Research Letters 14(4): 1-10.

Kinchy, Abby J. and Daniel Lee Kleinman. 2005. "Democratizing Science, Debating Values: New Approaches to 'Politicized' Science under the Bush Administration," Dissent 52(3, Summer): 54-62.

Ledford, Heidi, Sara Reardon, Emiliano Rodríguez Mega, Jeff Tollefson, and Alexandra Witze. 2019. "Trump Seeks Big Cuts to Science Funding - Again." Nature (March 11). [Ed: no 
volume to cite here.] http://www.nature.com/articles/d41586-019-00719-4. Accessed July 202019.

Massachusetts v. Environmental Protection Agency. 2007. 549 U.S. 497.

Mooney, Chris. 2005. The Republican War on Science. New York: Basic Books.

Otto, Shawn Lawrence. 2012. "America's Science Problem." Scientific American 307(5): 62-71 (1 November).

Rea, Christopher M. 2018. "Regulatory Thickening and the Politics of Market-Oriented Environmental Policy." Environmental Politics 28(7): 1167-1191.

Union of Concerned Scientists. 2018. "Abandoning Science Advice." Center for Science and Democracy at the Union of Concerned Scientists. (January). https:// www.ucsusa.org/sites/default/files/attach/2018/01/abandoning-scienceadvice-full-report.pdf. Accessed July 20, 2019.

USACE and EPA. 2019. Revised Definition of "Waters of the United States." Federal Register(84): 4154-4220.

U.S. Fish and Wildlife Service. 2018. "Endangered and Threatened Wildlife and Plants; Revision of the Regulations for Prohibitions to Threatened Wildlife and Plants." Federal Register(83): 35174-35178.

Williams, A. Park, et al. 2019. “Observed impacts of anthropogenic climate change on wildfire in California." Earth's Future (July 15). [Ed: no volume or page numbers to give here].

Zarefsky, David. 2007. "Making the Case for War: Colin Powell at the United Nations." Rhetoric and Public Affairs 10(2):275-302. 